\title{
PERANCANGAN APLIKASI PEMESANAN MENU MAKANAN DAN MINUMAN PADA CAFE LIVING ROOM BUKITTINGGI BERBASIS VB.NET 2010
}

\author{
Elmawati $^{1}$, Angga Sahputra ${ }^{2}$ \\ Sistem Informasi, Sekolah Tinggi Teknologi Industri Padang \\ E-mail: ${ }^{1}$ elmawati@sttind.ac.id, ${ }^{2}$ anggasahputra17@ gmail.com
}

\begin{abstract}
ABSTRAK
Application of manual work system has several advantages as it did in the café living room. Communication error on the availability of food and beverage menu that makes customer interaction with the waiter became longer because the waiter had to interact with the kitchen, the impact of this incident other customers have to wait when they want to order.To overcome this problem, an application was made ordering food and drink at the cafe living room-based multi-client using vb net in 2010. The use of multi-client choose to reduce the cost of an expensive resource.This design resulted in the application of food and beverage ordering menu-based multi-client that can be installed and run on a computer living room with exe format. With the implementation of this application customer's can order food menu and choose directly on the customer's computer are provided.
\end{abstract}

Keywords : Multi client, Applications menu reservations

\section{PENDAHULUAN}

Perkembangan teknologi yang sangat pesat, yang dibuktikan dengan penemuan teknologi baru yang memudahkan pekerjaan manusia. Setiap manusia menginginkan kemudahan dan kecepatan dalam memenuhi kebutuhanya, yang dulu hanya bisa dikendalikan secara manual sekarang bisa di kendalikan dengan teknologi. Apa lagi saat ini banyak terdapat cafe yang memanfaatkan teknologi sebagai sarana untuk meningkatkan mutunya mulai dari segi makanan, minuman, harga dan pelayanan.

Cafe Living Room merupakan cafe yang menjualmakanan dan minuman seperti pancake, puding, makanan fast food dan ice cream, dengan jumlah pengunjung kurang lebih 100 orang perhari.Pada kasus yang di dapat pada Cafe Living Room sering terjadi kesalahaan komunikasi antara pelayan dan kitchen tentang ketersedian menu makanan dan minuman sehingga membuat interaksi pelanggan dengan pelayan menjadi lama karena pelayan harus berinteraksi dengan kitchen, dampak dari kejadian ini pelanggan lain harus menunggu ketika ingin memesan.

Selain itu pelayan juga mengalami kesulitan ketika mencatat pesanan menu pelanggan yang dicatat secara manual di kertas. Pencatatan pesanan menu secara manual kurang efisien dari sisi waktu. Sistem komputerini pun di buat untuk memberikan pelayanan dan kepastian ketersediaan menu makanan dan minuman, dimana ketika ingin memesan, pelanggan melihat menu terlebih dahulu pada tombol menu di situ akan muncul gambar dan kode menu. Ketikaingin memesan pelanggan harus memasukkan kode menu pada datagried sesuai dengan pesanan yang diinginkanpelanggam dan jika menu makanan habis maka kitchen akan mengupdate data melalui kasir. Selain itu memberikan keamanan dan kepastian data.

Dari beberapa persoalan yang telah di paparkan di atas, penulis hendak memberikan pemecahannya dalam bentuk 
penelitian yang berjudul "Perancangan Aplikasi Pemesanan Menu Makanan dan Minuman Pada Cafe Living Room Bukittinggi Berbasis VB.Net”.

\section{METODOLOGI PENELITIAN}

\subsection{JenisPenelitian}

Jenis penelitian yang penulis lakukan adalah penelitian Terapan (Applied research). Penelitian terapan adalah penelitan yang hati-hati, sistematis dan terus menerus terhadap suatu masalah dengan tujuan digunakan segera untuk keperluan tertentu. Hasil penelitian tidak hanya sebagai suatu penemuan baru, tetapi merupakan aplikasi baru dari peneliti yang telah ada dan bermamfaat bagi Cafe Living Room.

\subsection{Data Dan Sumber Data}

Data-data yang dibutuhkan dalam penelitian ini ada 2 yaitu : data primer dan data sekunder.

a. Data Primer adalah data yang didapat langsung dari wawancara dengan Manejer dan Karyawan Cafe Living Room.

b. Data Sekunder

Data sekunder diperoleh dari Studi kepustakaan, dan buku-buku literatur lainya. Data sekunder meliputi nama, gambaran dan harga dari menu makanan dan minuman yang ada pada Cafe Living Room.

\section{ANALISA DAN DESAIN SISTEM}

\subsection{Analisa Sistem}

Analisa sistem merupakan suatu istilah secara kolektif yang mendeskripsikan fase-fase awal pengembangan sistem dan teknik pemecahan masalah yang menguraikan bagian-bagian dari komponen yang bekerja dan berinteraksi untuk mencapai suatu tujuan. Analisa sistem merupakan tahap yang paling awal dari pengembangan sistem

\subsection{Analisa Sistem Yang Sedang Berjalan}

Dalam pengolahan suatu data perusahaan atau instansi menginginkan penyajian informasi yang akurat, bilamana penyajian informasi yang dilakukan masih secara manual dan dimana hal ini tidak sesuai lagi dengan zaman teknologi yang memanfaatkan segalanya.Dengan teknologi komputer yang dapat membantu pengolahan data yang efektif dan efisien.

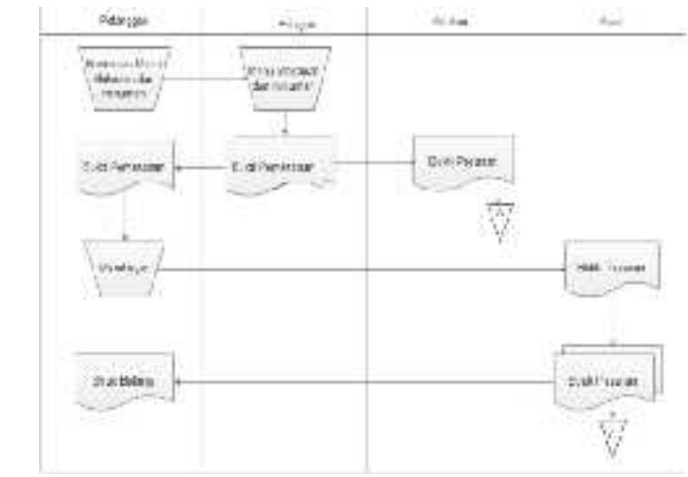

Gambar 1. Aliran Sistem Informasi Lama

Adapun gambaran dari Aliran Sistem Lama adalah sebagai berikut :

1. Pelanggan memesan menu yang ada pada daftar menu.

2. Setelah itu pelayan mencatat menu pesanan yang di pesan pelanggan, seterusnya di berikan ke pelanggan sebagai bukti pemesanan dan ke kitchen.

3. Ketika pelanggann ingin membayar, pelanggan harus membawa bukti pesanan ke kasir.

4. Selanjutnya kasir membuatkan struk belanja dan memberikan ke pelanggan.

\subsection{Desain Global}

Desain global merupakan salah satu bentuk gambaran dari perancangan data secara umum. Desain global dapat digambarkan dengan menggunakan Aliran Sistem Informasi ( ASI ) baru, DFD ( Data Flow Diagram ), dan ERD (Entity Relathionship Diagram ) yang dijabarkan oleh simbol-simbol/ diagram. 


\subsection{Analisa Sistem Yang Diusulkan}

Pada sistem baru ini proses pengolahan data nilai untuk laporan pada kepala sekolah dapat diberikan pada saat dibutuhkan karena informasi yang diperlukan sudah tersedia pada bagian tata usaha.

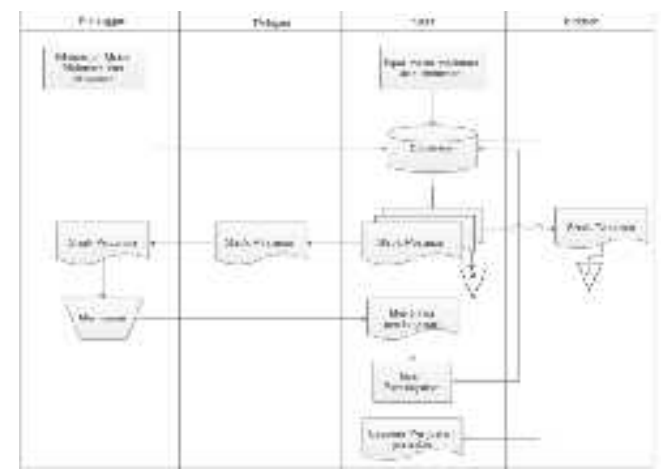

Gambar 2. Aliran Sistem Informasi Baru

Adapun gambaran dari Aliran Sistem Baru adalah sebagai berikut :

1. Pelanggan memilih menu makan dan minuman langsung di komputer yang telah di sediakan.

2. Data akan masuk ke database dan akan terprint di mesin print yang di sediakan di bagian kasir.

3. Struk akan di print sebanyak 3 lembar (pelanggan, kitchen dan kasir).

4. Pada bagian kasir terdapat laporan penjualan, serta dapat menginputkan stock makanan dan input pembayaran.

5. Ketika pelayan ingin membayar, pelanggan harus membawa struk ke kasir.

\subsection{Context Diagram}

Context diagram digunakan untuk menjelaskan siapa-siapa saja ( Entityentity) yang terlibat dalam suatu sistem pengolahan data. Dari context diagram ini dijelaskan juga arus dari pengolahan secara garis besarnya.Pada Cafe Living Room Bukittinggi. Adapun bentuk diagram tersebut yaitu sebagai berikut:
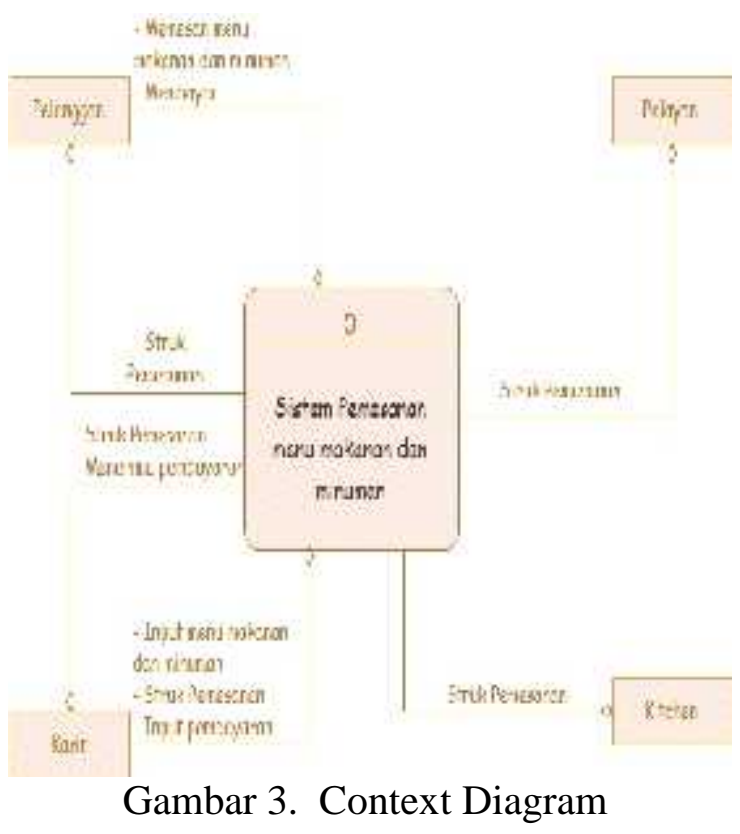

Adapun gambaran dari Data Flow Diagram adalah sebagai berikut :

1. Pada sistem pemesanan menu makanan dan minuman pada cafe living room bkittinggi kasir mengimput menu makanan dan minuman

2. Pelanggan yang datang langsung memilih menu makanan dan minuman di komputer yang di sediakan serta menerima struk dan melakukan pembayaran langsung ke kasir.

3. Kasir menerima struk pemesanan dan di berikan ke kitchen, pelanggan dan pelayan, serta menerima uang pembayaran dari pelanggan.

\subsection{Data Flow Diagram}

Merupakan pengembangan dari DFD untuk memperlihatkan data berupa file-file data maupun data base. Untuk DFD level nol mirip dengan context diagram namun di tambahkan dengan data basenya. Adapun diagramnya sebagai berikut: 


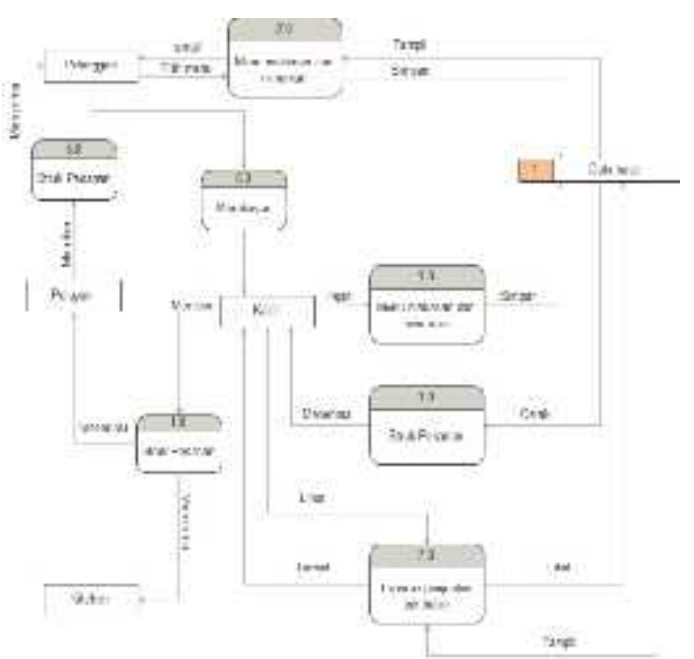

Gambar 4. Data Flow Diagram

Adapun gambaran dari Data Flow Diagram adalah sebagai berikut :

1. Kasir menginputkan menu makanan dan minuman, menerima pembanyaran dan melihat laporan penjualan

2. Pelanggan Memilih menu yang di tampilkan dari data base, menerima struk dari pelayan dan membayar ke kasir.

3. Pada bagian kasir menerima struk pesanan pelayan, memberikan struk ke pelayan dan kitchen.

\subsection{ERD}

Entity relationship ini digunakan untuk menggambarkan hubungan antara file-file yang digunakan dalam sistem ini. Adapun diagramnya sebagai berikut :

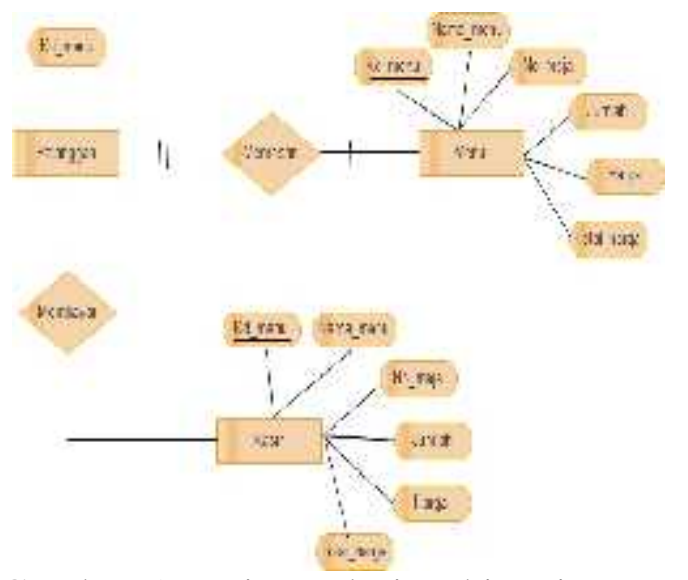

Gambar 5. Entiry Relasionship Diagram

\subsection{Desain Data Base}

Desain ini merupakan suatu masukan atau input database yang telah penulis buat pada awal pembuatan program dimana database tersebut kumpulan dari beberapa file yang saling berhubungan antara satu dengan yang lainnya. Kelebihan database dengan MySql ini yaitu desainnya lebih mudah serta koneksi tidak terlalu rumit. Bentuk file yang saling berhubungan dalam Perancangan Aplikasi Pemesanan Menu Makanan dan Minuman Pada Cafe Living Room Bukittinggi yaitu Sebagai berikut :

a. Desain tabel Form Menu

Desain tabel form menu dapat di lihat pada tabel 1.

Tabel 1. Tabel Menu

\begin{tabular}{|c|c|c|c|c|}
\hline No & $\begin{array}{c}\text { Field } \\
\text { Name }\end{array}$ & $\begin{array}{l}\text { Type } \\
\text { Data }\end{array}$ & $\begin{array}{c}\text { Field } \\
\text { Size }\end{array}$ & Ket \\
\hline 1 & $\begin{array}{l}\text { kode_ } \\
\text { menu }\end{array}$ & Text & & $\begin{array}{l}\text { Prima } \\
\text { ryKey }\end{array}$ \\
\hline 2 & $\begin{array}{l}\text { Nama_ } \\
\text { menu }\end{array}$ & Text & & \\
\hline 3 & jumlah & Int & 20 & \\
\hline 4 & Harga & Int & 20 & \\
\hline
\end{tabular}

b. Desain Form Kasir

Desain tabel form kasir dapat di lihat pada tabel 2.

Tabel 2. Tabel Kasir

\begin{tabular}{|c|l|c|c|c|}
\hline No & \multicolumn{1}{|c|}{$\begin{array}{c}\text { Field } \\
\text { Name }\end{array}$} & $\begin{array}{c}\text { Type } \\
\text { Data }\end{array}$ & $\begin{array}{c}\text { Field } \\
\text { Size }\end{array}$ & Ket \\
\hline 1 & $\begin{array}{l}\text { no_faktu } \\
\text { r }\end{array}$ & Text & & \\
\hline 2 & Tanggal & $\begin{array}{c}\text { Dateti } \\
\text { me }\end{array}$ & & \\
\hline 3 & item & Int & 11 & \\
\hline 4 & Total & Int & 11 & \\
\hline 5 & Kodeptg & Text & & \\
\hline
\end{tabular}




\section{IMPLEMENTASI SISTEM}

\subsection{Implementasi Sistem}

Implementasi sistem adalah suatu prosedur yang di lakukan pada tahap sistem dalam dokumen yang disetujui dan menguji kemudian menginstal dan menggunakan program yang di buat.

\subsection{Tahapan Implementasi Sistem}

1. Perencanaan dan proses implementasi

2. Pelaksanaan proses implementasi

3. Pelatihan Personil

\subsection{Pemrograman}

Penulisan atau penyajian program kedalam bahasa komputer, dalam hal ini visual basic.net 2010sebagai program untuk menjalankan program dan melakukan pengujian kesalahan program.

\subsection{Instalasi Hardware dan Software}

Agar sistem baru dapat berjalan sesuai dengan harapan, maka dibutuhkan instalasi terhadap hardware dan software yang akan digunakan dalam pengimplementasian aplikasi pemrograman visual basic yang telah dirancang. Sehingga memudahkan user dalam menggunakan program aplikasi yang telah dirancang.

\subsection{Menu Aplikasi Pemesanan}

Menu merupakan jalur pemakai yang mudah dipahami dan digunakan dalam pengolahan data. Menu berisi beberapa pilihan yang disajikan kepada pemakai, Pemakai dapat memilih pilihan di menu dengan cara menggerakkan kursor. Struktur menu merupakan gambaran mengenai isi dari keseluruhan program yang dibuat. Struktur menu dari program aplikasi ini adalah sebagai berikut :

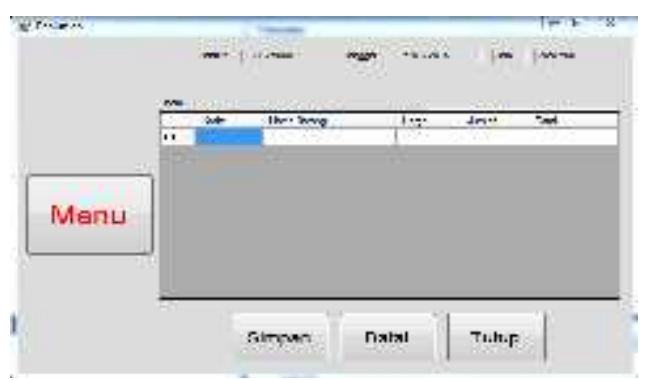

Gambar 6. Desain Form Pemesanan

Gambar Desain Form Menu dapat di lihat pada gambar 7

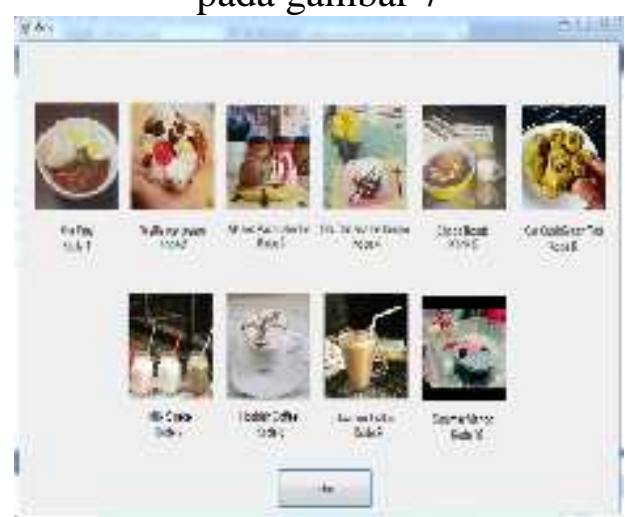

Gambar 7. Desain Form Menu

Dari form pelanggan/penjualan diatas tinggal melihat menu yang ada pada form menu dengan cara klik pada tombol menu dan melihat menu beserta kode menu. Jika pelanggan sudah menentukan pilihan tinggal mengetikkan kode menu pada kolom kode pada DataGriedView dan mengisian jumlah pesanan di DataGriedView pada colom jumlah dengan klik dua kali seterusnya klik pesan maka pesanan akan tersimpan di database dan akan terprint. Gambar Desain Form Login dapat di lihat pada gambar 8 .

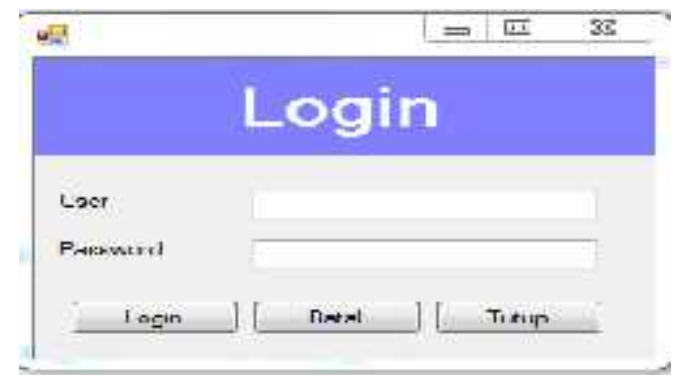

Gambar 8. Desain Form Login

Pada form login admin (kasir) harus memasukkan username dan password dengan benar untuk bisa masuk ke dalam form aplikasi penjualan kasir. Jika salah 
dalam mamasukkan username dan password maka akan ada pemberitahuan bahwa username dan password yang di masukkan salah.

\subsection{Desain From Aplikasi Penjualan Kasir}

Gambar Desain Form Aplikasi penjualan

Kasir dapat di lihat pada gambar 9.

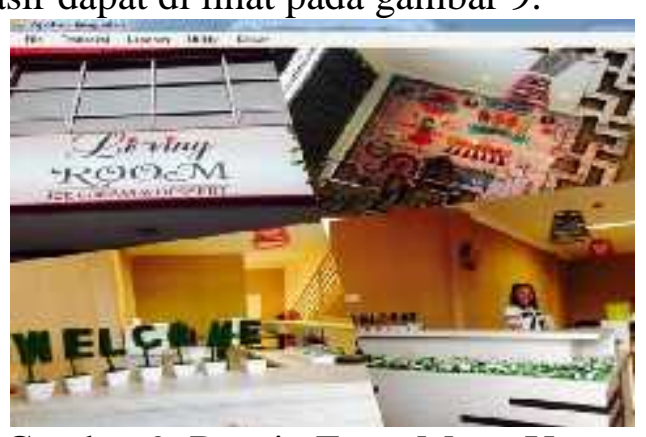

Gambar 9. Desain From Menu Utama

Gambar Desain Form Pembayaran (Kasir) dapat di lihat pada gambar 10.

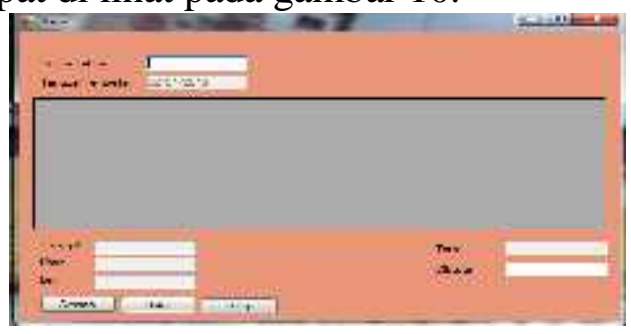

Gambar 10. Desain Form Pembayaran (Kasir)

Gambar Desain Form Input Menu dapat di lihat pada gambar 11 .

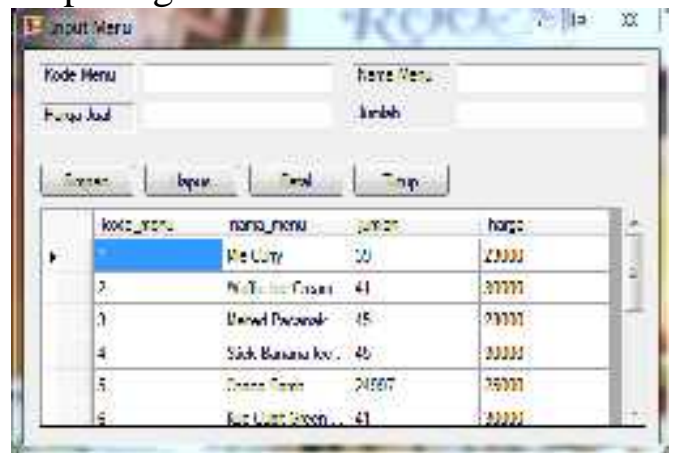

Gambar 11. Desain Form Input Menu

Gambar Desain Form Petugas dapat di lihat pada gambar 12.

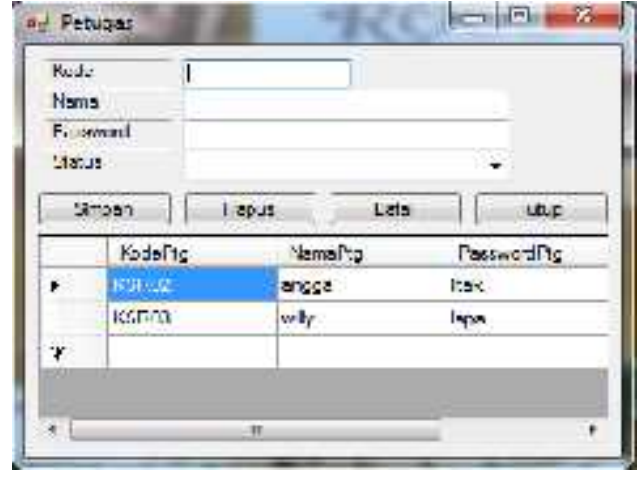

Gambar 12. Desain Form Petugas

Gambar Desain Form Ganti Pasword dapat di lihat pada gambar 13.

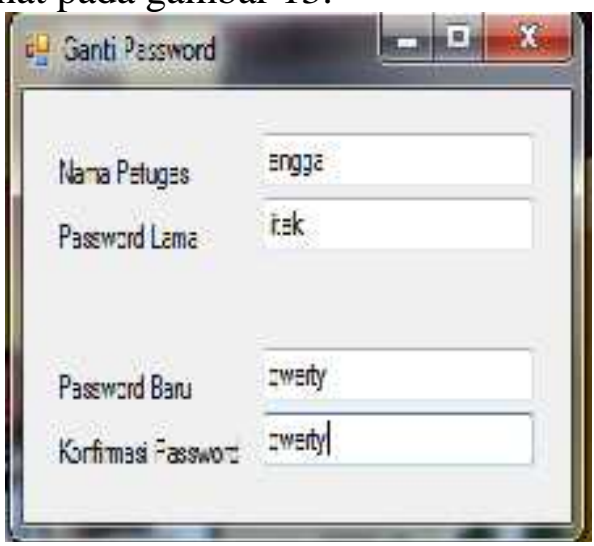

Gambar 13. Desain Form Ganti Password

Gambar struk pemesanan dapat di lihat pada gambar 14 .

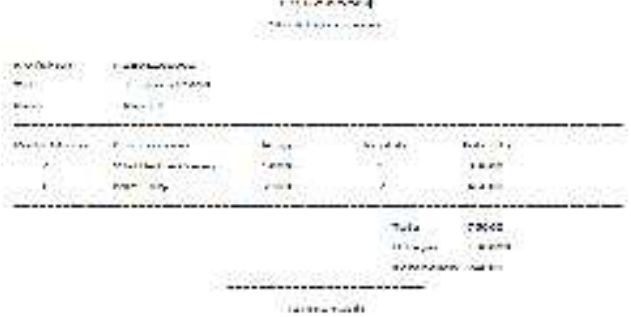

Gambar 14. Struk Pemesanan

Gambar Laporan Perbulan dapat di lihat pada gambar 15 .

IA XORAN FFH III AN FERRII AN

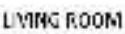

\begin{tabular}{|c|c|c|c|c|c|}
\hline hos: $: 1-1$. & Hinikiresi & " & fiwl?h & 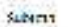 & [avd. \\
\hline काxyal & kieldy & +5.00 & I & 18.00 & 2012 \\
\hline $2 x . .6 \times 3$ & Toertif from Tix & $m$ & 1 & $\mathrm{~mm}$ & 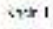 \\
\hline $2 x: 5 \times x: 2$ & 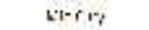 & סדיו & 1 & חויו & $\leqslant 1$ \\
\hline WXYY & का. मू. & $2: 2500$ & $!$ & $\$ 1500$ & 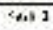 \\
\hline $2 x . x \times: 2$ & saresekeren & mos & 4 & $1 \mathrm{mos}$ & Si. 1 \\
\hline
\end{tabular}

Gambar 15. Laporan Perbulan 
Pada Form Aplikasi Pnjualan Kasir ini terdapat beberapa form yang di gunakan untuk berbagai keperluan kasir seperti: Input Menu, Pembayar, Rincian Penjualan, Laporan Perbulan, Struk Pemesanan dan Mengubah password / data petugas.

\section{KESIMPULAN DAN SARAN}

Berdasarkan penelitian tentang perancangan aplikasi pemesanan menu makanan dan minuman yang penulis buat maka kesimpulan sebagai berikut :

1. Aplikasi ini lebih efektif dan efisien bila dibandingkan dengan sistem lama yang digunakan pada Cafe Living Room tersebut. Sistem ini memberikan kemudahan dalam pemilihan menu makanan dan minuman, serta harga yang sudah tersaji dengan baik di layar komputer yang di khususkan untuk pelanggan.

2. Aplikasi pemesanan menu makanan dan minuman ini sudah mempunyai database yang sudah terprogram sehingga aplikasi ini dapat membantu dan memudahkan kasir dalam pembuatan laporan penjualan setiap bulannya.

\section{DAFTAR PUSTAKA}

Al Fatta, Hanif, Analisis \& Perancangan Sistem Informasi untuk Keunggulan Bersaing Perusahaan \& Organisai Modern, Andi Offset, Yogyakarta, 2007.

Kurniawan, Erik, M.kom, Cepat Mahir Visual Besic 2010. Andi Offset, yogyakarta,2010

Safrizal, Melwin, Pengantar Jaringan Komputer, Andi Offset, Yogyakarta, 2005.

Sutabri, Tata, Konsep Sistem Informasi, Andi Offset, Yogyakarta, 2012

Sutarman, Pengantar Teknologi Informasi, Bumi Aksara, Jakarta 2012
Wahyudi, Bambang, S.Kom, MMSi, Konsep Sistem Informasi dari Bit sampai ke Database, Andi Offset, Yogyakarta, 2008.

http://id.m.wikipedia.org/wiki/Visual_Besi c_.NET,di akse pada 15 November 2015

www.semukan.com/2015/01/pengertianmysql.html?m=1, di akses pada 15 November 2015 